\title{
Heterobimetallic Aryloxides of Titanatranes with Aluminum Alkyls for Ring opening polymerization (ROP) of rac-Lactide
}

\author{
Prabhuodeyara M Gurubasavaraj* \\ Department of Chemistry, Rani Channamma University, India
}

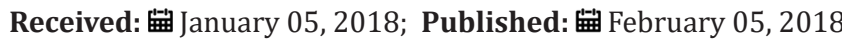

*Corresponding author: Prabhuodeyara M Gurubasavaraj, Department of Chemistry, Rani Channamma University, PBNH-4 Vidyasangama, Belagavi-596156 India, Email: pmg@rucb.ac.in

\section{Abstract}

The titanatrane titanium complexes were treated with Aluminum Alkyls to prepare their bimetallic derivatives (1a-4a). The compounds were confirmed by means of NMR and elemental analysis. The complexes were used as catalysts for ring opening polymerization of racemic lactide. The complexes exhibit high activity and selectivity in the polymerization process.

Abbreviations: ROP: Ring Opening Polymerization; LA: Rac-lactide

\section{Introduction}

Olefin polymerization catalysis [1a-1b] continues to be an area of considerable importance to both the academic and industrial communities, and a wide range of reports are appearing on the efficient catalyst designs and application in various catalytic systems. Recently, the work on bimetallic complexes and in particularly bimetallic oxides is gaining considerable attention due to the "cooperativity" or "communication" between neighboring repeating units [2a-2d]. Since heterometallic alkoxides are potential molecular precursors of multicomponent oxides, they are thus of interest for applications in catalysis as well as in material science. Heterometallic alkoxide derivatives have been postulated to act as catalysts in Ziegler-Natta polymerization [3a,3b] or olefin metathesis reactions, $[3 c]$ and exhibit high activity and produce polymers with different microstructure. These heterometallic complexes were also found active in nitrogen activation," but detailed characterization is lacking [4].

The main disadvantage of mononuclear catalysts is the need of large amount of MAO or expensive fluorinated borate activators to obtain adequate polymerization activity, which causes concern over the high cost of metallocene catalysts and the high ash content $\left(\mathrm{Al}_{2} \mathrm{O}_{3}\right)$ of the product polymers. Consequently, there is a great need to develop new catalyst systems that can provide high catalytic activity with no need for a large amount of expensive cocatalysts. We were thus interested in designing the catalysts which can exhibit high activity in the polymerization without or with very less amount of cocatalysts. For this, we used atrane ligands which have a nitrogen atom that facilitates coordination in a chelate fashion when necessary by providing the metal with additional electronic density [5a-e]. Although there have been many reports on the complexes based on atrane ligands, application of these complexes in polymerization reactions are very limited [6a-c].

We recently reported that heterobimetallic complexes of titanium iso-propoxide and aluminum alkyl containing bis (aryloxo) ethanolamine ligand were effective as catalysts precursor for ethylene polymerization even in the absence of cocatalysts [7]. We then extended the chemistry to tris (aryloxo) amine based ligands [8]. Furthermore, we reported that titanatranes bearing terminal substituted aryloxo ligands exhibit the highest activity in ethylene polymerization [9]. To the best of our knowledge these complexes are the best catalysts for ethylene polymerization among all the titanatranes reported so far. We became interested in isolating the bimetallic complexes of titatnium bearing aryloxo terminal ligands with aluminum alkyls to understand the plausible mechanism of polymerization process and the effect of substituents on the nature of heterobimetallic complexes. In this contribution we report the isolation, structural characterization of the titanatranes bearing aryloxo terminal ligand with the aluminum alkyls and their catalytic activity in ethylene and Ring Opening Polymerization (ROP) of raclactide. 


\section{Results and Discussion}

The titanatranes and their bimetallic derivatives are prepared as reported earlier [8]. The following complexes were confirmed by NMR and elemental analysis. The pure crystalline products were used for the polymerization process (Figure 1). There has been considerable attention on the study of ring-opening polymerization (ROP) of cyclic esters such as rac-lactide (LA) with metal complexes for the past few decades [10a-b]. Various types of metal alkoxides such as tin [11a-e], aluminum, zinc, magnesium, iron [12a-b], lanthanide [13a-c], and lithium [14] organometallic complexes have been found to be active LA polymerization catalysts, and many afford materials with controlled molecular weights and narrow molecular weight distributions. Despite the fact that some excellent initiators have been reported for the polymerization of LA, the search for new catalysts that generate well-defined polylactides remains of keen interest. The roles of the structure of metal alkoxide complexes in determining molecular weights and molecular weight distributions, as well as the polymerization pathway, are significant current research issues.

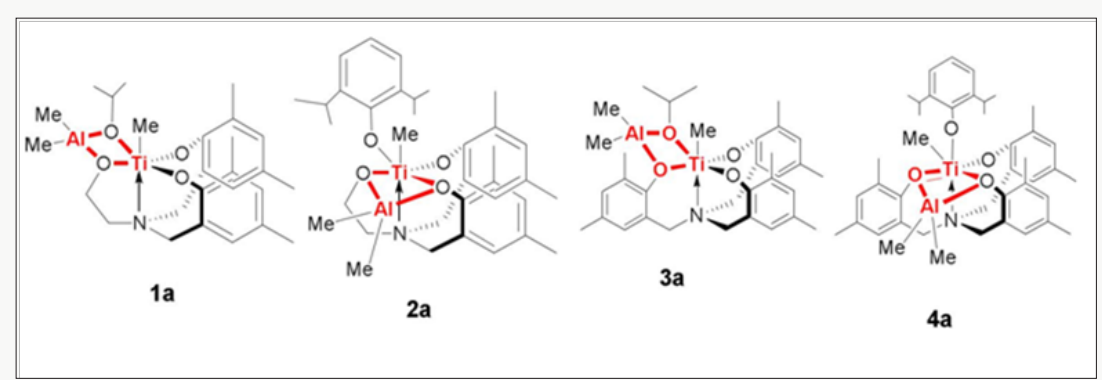

Figure 1: Bulk Polymerization of rac-Lactide (rac-LA).

Recently, Verkade et al. [15a-b] reported that several titanium alkoxides showed reasonably good catalytic activity in the bulk homopolymerization of rac-LA at $130{ }^{\circ} \mathrm{C}$. Harada et al. [16] also reported the living polymerization of LA by a Ti chloride complex, whose chloride apparently plays the same role as an alkoxide. We thus believed it would be interesting to test heterobimetallic titanium catalysts and compare the activity and control of the molecular and physical properties of the PLA produced by mononuclear and binuclear complexes with well-defined ligand environments. Here, we describe discrete heterobimetallic titanium alkoxide/aryloxide complexes and their bimetallic derivatives for the study of the ROP of LA under bulk polymerization conditions. We also demonstrate the difference in monometallic and bimetallic catalysts towards the ROP of rac-Lactide.

Table 1: Ring opening polymerization (ROP) of rac-Lactide Data for Heterobimetallic complexes.

\begin{tabular}{|c|c|c|c|c|c|c|}
\hline Run & Complex & g polymer & Yield & $\mathbf{M}_{\mathbf{w}}{ }^{\mathbf{b}}$ & $\mathbf{M n}^{\mathbf{b}}$ & $\mathbf{M}^{\mathrm{w}} / \mathbf{M}_{\mathbf{n}}{ }^{\mathbf{c}}$ \\
\hline 1 & $1 \mathrm{a}$ & 1.82 & 91 & 64009 & 49045 & 1.31 \\
\hline 2 & $2 \mathrm{a}$ & 1.68 & 84 & 81725 & 53373 & 1.53 \\
\hline 3 & $3 \mathrm{a}$ & 1.76 & 88 & 48.104 & 38115 & 1.26 \\
\hline 4 & $4 \mathrm{a}$ & 1.80 & 90 & 61076 & 44188 & 1.38 \\
\hline
\end{tabular}

$\mathrm{LA}(2.027 \mathrm{~g}) \mathrm{LA} / \mathrm{Ti}=300$, polymerization temperature $=130^{\circ} \mathrm{C}$, time $=20 \mathrm{~min}$.

The weight average molecular weight $\left(M_{w}\right)$, the number average molecular weight $\left(M_{n}\right)$, and the polydispersity index (PDI) $\left.M_{w} / M_{n}\right)$ were determined by GPC.
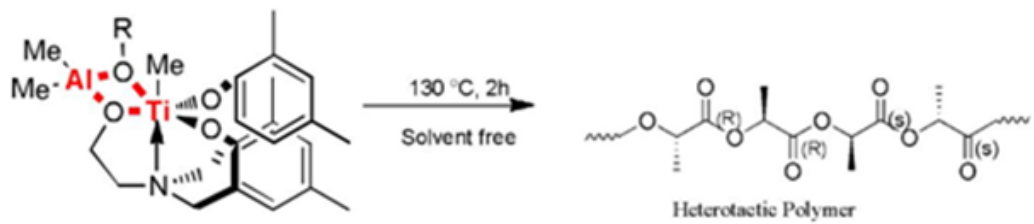

Figure 2. 
The preference for heterotacticity in our poly (rac-LA) are comparatively stronger for bimetallic complexes than their mononuclear precursor compounds and are similar to the previous reports by Kasperczyk et al. [17]. This may be due to the initiating alkoxide/aryloxide group which dissociate relatively easily from the titanium in bimetallic complexes than their monometallic precursors in the early stage of polymerization so that it can be utilized to initiate LA polymerization and provide a means of controlling the molecular weight by functioning as an end group. It appears that the initiating group is the highly bulky i-Pr alkoxide (in 1 and 3 ) or i-Pr-phenolate ( 2 and 4) group in monometallic, similar to the observation made by Verkade et al. [15] But the scenario in bimetallic complexes is complicated. We assume that the initiating group may be similar to the mononuclear complexes, although the insertion of lactide into Ti-O of the aryloxo arm or alkoxo arm cannot be ruled out (Figure 2) and (Table 1).

\section{Concluding remarks}

The titanatrane titanium complexes and their bimetallic derivatives exhibit high activity and selectivity in bulk polymerization of rac-Lactide. Bimetallic complexes (Ti-Al) exhibit higher activity and produces high molecular weight compared to their monometallic counterpart [5b]. This may be due to the better electronic and steric environment in bimetallic complexes. The polylactide obtained in this process is heterotactic in nature. Further investigations of mechanism in this process are on in our laboratory.

\section{Experimental Section}

General Procedures. All experimental manipulations were carried out under an atmosphere of dry nitrogen using standard Schlenk techniques or using a Vacuum Atmospheres drybox unless otherwise specified. All chemicals used were of reagent grades and were purified by standard purification procedures. Toluene (anhydrous grade, Kanto Kagaku Co., Ltd.) and n-octane (anhydrous grade, Aldrich) for polymerization were stored in a bottle in the drybox in the presence of molecular sieves (a mixture of $3 \mathrm{~A} 1 / 16$, $4 \mathrm{~A} 1 / 8$, and $13 \mathrm{X} 1 / 16$ ). Polymerization grade ethylene (purity > 99.9\%, Sumitomo Seika Co. Ltd.) was used as received. Toluene and AlMe3 from the commercially available methylaluminoxane [PMAO-S, 9.5wt\% (Al) toluene solution, Tosoh Finechem Co.] were removed under reduced pressure (at ca. $50{ }^{\circ} \mathrm{C}$ for removing toluene and AlMe3 and then heated at $>100{ }^{\circ} \mathrm{C}$ for $1 \mathrm{~h}$ for completion) in the drybox to give white solids. Bis (2-hydroxy-3,5-dimethylbenzyl) ethanolamine and tris(2-hydroxy-3,5-di-tert-butylbenzyl)amine were prepared according to a published procedure [18]. The titanatranes containing phenoxy terminal ligands Ti(0-2,6iPr2C6H3) $\{(\mathrm{O}-2,4-\mathrm{Me} 2 \mathrm{C} 6 \mathrm{H} 2-6-\mathrm{CH} 2) 2(\mathrm{OCH} 2 \mathrm{CH} 2) \mathrm{N}\}$ and $\mathrm{Ti}(\mathrm{O}-2,6-$ iPr2C6H3) [(O-2,4-Me2C6H2-6-CH2)3N] were prepared according to the previous report [9].

Molecular weights and molecular weight distributions for polyethylene were measured by gel permeation chromatography
(Tosoh HLC- 8121GPC/HT) with a polystyrene gel column (TSK gel GMHHR-H HT $\times 2,30 \mathrm{~cm} \times 7.8 \mathrm{~mm} \phi$, ranging from $<102$ to $<2.8 \times 108$ MW) at $140{ }^{\circ} \mathrm{C}$ using o-dichlorobenzene containing $0.05 \mathrm{w} / \mathrm{v} \%$ 2,6-di-tert-butyl-p-cresol as eluent. The molecular weight was calculated by a standard procedure based on the calibration with standard polystyrene samples. All $1 \mathrm{H}$ and $13 \mathrm{C}$ NMR spectra were recorded on a JEOL JNMLA 400 spectrometer $(399.65 \mathrm{MHz}$ for $1 \mathrm{H}$, $100.626 \mathrm{MHz}$ for 13C). All deuterated NMR solvents were stored over molecular sieves under a nitrogen atmosphere in the drybox, and all chemical shifts are given in ppm and referenced to SiMe4 (TMS). All spectra were obtained in the solvent indicated at $25{ }^{\circ} \mathrm{C}$ unless otherwise specified. Elemental analyses were performed by using PE2400II Series (Perkin-Elmer Co.) [19].

Procedure for rac-Lactide Polymerization, LA bulk polymerizations were carried out by charging a stirring bar, $2.00 \mathrm{~g}$ of LA, and then the appropriate amount of catalyst precursor to a $10 \mathrm{ml}$ Schlenk flask. The flask was then immersed in an oil bath at $130{ }^{\circ} \mathrm{C}$, and after the appropriate time, the reaction was terminated by the addition of $5 \mathrm{ml}$ of methanol. The precipitated polymers were dissolved in a minimum amount of methylene chloride, and then, excess methanol was added. The resulting reprecipitated polymers were collected, washed with $50 \mathrm{ml}$ of methanol, and dried in vacuo at $50{ }^{\circ} \mathrm{C}$ for $12 \mathrm{~h}[20 \mathrm{a}-\mathrm{b}]$.

\section{References}

1. (a) Britovsek GJP, Gibson VC, Wass DF (1999) the search for new generation olefin polymerization catalysts: life beyond metallocenes. Angew Chem Int Ed Engl 38: 428-447.

(b) McKnight AL, Waymouth RM (1998) Group 4 ansa-Cyclopentadienyl-Amido Catalysts for Olefin Polymerization Chem Rev 98(7): 25872598.

2. (a) Caulton KG, Hubert-Pfalzgra LG (1990) Synthesis, structural principles and reactivity of heterometallic alkoxides. Chem Rev 90(6): 969995.

(b) Gurubasavaraj PM, Roesky HW, Veeresha Sharma PM, Oswald RB, Dolle V, et al. (2007) Oxygen Effect in Heterobimetallic Catalysis: The Zr-0-Ti System as an Excellent Example for Olefin Polymerization. Organometallics 26: 3346-3351.

(c) Gurubasavaraj PM, Mandal SW, Roesky HW, Oswald RB, Pal A, et al. (2007) Synthesis and X-ray

Structural Characterization of Oxygen Bridged Complexes for Olefin Polymerization: A Theoretical Interpretation of Structure and Activity Relationship. Inorg Chem 46: 1056.

(d) Gurubasavaraj PM, Roesky HW, Nekouelsharaki B, Pal A, Herbst-Irmer R (2008) Inorg Chem 47: 5324.

3. (a) Berger E (1974) Ger Offen 232476 (Solvay \& Cie)

(b) Capshew CE (1980) Eur Pat Ap 1: 7425 (Philips Petroleum Co)

(c) Sinn H, Kaminsk W (1980) Adu Organomet Chem18: 99.

4. Volpin ME (1980) J Organomet Chem pp. 200-319.

5. (a) Voronkov MG, Dyakov VM, Kirpichenko SV (1982) J Organomet Chem p. 233.

(b) Verkade JG (1993) Atranes: new examples with unexpected properties. Acc Chem Res 26(9): 483-489. 
(c) Verkade JG (1994) Cood Chem Rev 137: 233.

(d) Schrock RR (1997) Transition Metal Complexes That Contain a Triamidoamine Ligand. Acc Chem Res 30(1): 9-16.

(e) Gade LH (2000) Chem Commun p. 173.

6. (a) Kim Y, Hong E, Lee MH, Kim J, Han Y, et al. (1999) Organometallics 18: 36 .

(b) Wang W, Fujiki M, Nomura K (2004) Cover Picture: Macromol. Rapid Commun. 3/2004. Rapid Commun 25(3): 504.

(c) Padmanabhan S, Wnag W, Katao S, Nomura K (2007) Macromol Symp 260: 133.

7. Padmanabhan S, Katao S, Nomura K (2007) Synthesis and Structure of Titanatranes Containing Tetradentate Trianionic Donor Ligands of the Type $\left[\left(\mathrm{O}-2,4-\mathrm{R}_{2} \mathrm{C}_{6} \mathrm{H}_{2}-6-\mathrm{CH}_{2}\right)_{2}\left(\mathrm{OCH}_{2} \mathrm{CH}_{2}\right)\right] \mathrm{N}_{3}-$ and Their Use in Catalysis for Ethylene Polymerization. Organometallics 26(7): 1616-1626.

8. Gurubasavaraj PM, Nomura K Organometallics.

9. Gurubasavaraj PM, Nomura K (2009) Synthesis and structural analysis of titanatranes bearing terminal substituted aryloxo ligands of the type [Ti(OAr) $\left.\left\{\left(\mathrm{O}-2,4-\mathrm{Me}_{2} \mathrm{C}_{6} \mathrm{H}_{2}-6-\mathrm{CH}_{2}\right)_{2}\left(\mathrm{OCH}_{2} \mathrm{CH}_{2}\right) \mathrm{N}\right\}\right] \mathrm{n}(\mathrm{n}=1,2)$ : effect of aryloxo substituents in the ethylene polymerization Inorg Chem 48(19): 9491-9500.

10. (a) Kuran W (1998) Prog Polym Sci 23: 919.

(b) O'Keefe BJ, Hillmyer MA, Tolman WB (2001) Polymerization of lactide and related cyclic esters by discrete metal complexes. J Chem Soc Dalton Trans 2(2): 15.

11. (a) Nijenhuis AJ, Grijpma DW, Pennings AJ (1992) Lewis acid catalyzed polymerization of L-lactide. Kinetics and mechanism of the bulk polymerization. Macromolecules 25(24): 6419-6424.

(b) Kricheldorf HR, Lee SR, Bush S (1996) Polylactones 36. Macrocyclic Polymerization of Lactides with Cyclic $\mathrm{Bu}_{2} \mathrm{Sn}$ Initiators Derived from 1,2-Ethanediol, 2-Mercaptoethanol, and 1,2-Dimercaptoethane. Macromolecules 29(5): 1375-1381.

(c) Kowalski A, Libiszowski J, Duda A, Penczek S (2000) Macromolecules 33: 1964 .

(d) Stridsberg K, Ryner M, Albertsson AC (2000) Mechanism of Cyclic Ester Polymerization Initiated with Tin(II) Octoate. 2 Macromolecules Fitted with Tin(II) Alkoxide Species Observed Directly in MALDI-TOF Spectra. Macromolecules 33(3): 689-695.

(e) Dove AP, Gibson VC, Marshall EL, White AJP, Williams DJ (2001) A well defined tin(II) initiator for the living polymerisation of lactide. Chem Commun 283.
12. (a) Ovitt TM, Coates GW (1999) Stereoselective Ring-Opening Polymerization of meso-Lactide: Synthesis of Syndiotactic Poly(lactic acid). J Am Chem Soc 121(16): 4072-4073.

(b) Nomura N, Ishii R, Akakura M, Aoi KJ (2002) Stereoselective ring-opening polymerization of racemic lactide using aluminum-achiral ligand complexes: exploration of a chain-end control mechanism. Am Chem Soc 124(21): 5938-5939.

13. (a) Chisholm MH, Eilerts NW (1996) Chem Commun p. 853.

(b) Cheng M, Attygalle AB, Lobkovsky EB, Coates GW (1999) Single-Site Catalysts for Ring-Opening Polymerization: Synthesis of Heterotactic Poly(lactic acid) from rac-Lactide. J Am Chem Soc 121(49): 1158311584.

(c) Chamberlain BM, Jazdzewski BA, Pink M, Hillmyer MA, Tolman WB (2000) Controlled Polymerization of dl-Lactide and $\varepsilon$-Caprolactone by Structurally Well-Defined Alkoxo-Bridged Di- and Triyttrium(III) Complexes. Macromolecules 33 (11):3970-3977.

14. Ко BT, Lin CC (2001) Synthesis, Characterization, and Catalysis of Mixed-Ligand Lithium Aggregates, Excellent Initiators for the Ring-Opening Polymerization of l-Lactide. J Am Chem Soc 123(33): 7973-7977.

15. (a) Kim Y, Verkade JG (2002) Organometallics 21: 2395.

(b) Kim Y, Kapoor PN, Verkade JG (2002) (RO)(2)Ta[tris(2-oxy-3,5-dimethylbenzyl)amine]: structure and lactide polymerization activities. Inorg Chem 41(18): 4834-4838.

16. Takashima Y, Nakayama Y, Watanabe K, Itono T, Ueyama N, et al. (2002) J Macromolecules 35: 7538.

17. Kasperczyk JE (1995) Microstructure Analysis of Poly (lactic acid) obtained by Lithium tert-Butoxide as Initiator. Macromolecules 28(11): 3937-3939.

18. Kol M, Shamis M, Goldberg I, Goldschmidt Z, Alfi S, et al. (2001) Inorg Chem Commun 4: 177.

19. Beurskens PT, Admiraal G, Beurskens G, Bosman WP, De Delder R, et al. (1994) The DIRDIF94 program system, Technical report of crystallography laboratory, University of Nijmegen, Netherlands.

20. (a) Crystal Structure 3.6.0. Crystal Structure Analysis Package, Rigaku and Rigaku/MSC (2000-2004) 9009 New Trails, Dr. The Woodlands TX 77381 USA.

(b) Watkin DJ, Prout CK, Carruthers JR, Betteridge PW (1996) Chemical Crystallography Laboratory, Oxford, UK CRYSTALS Issue 10.

\section{AOICS}

DOI: 10.32474/AOICS.2018.01.000110

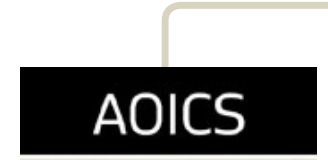

Archives of Organic and Inorganic Chemical Sciences

\section{Assets of Publishing with us}

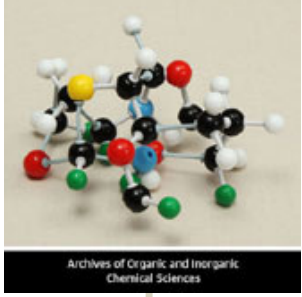

- Global archiving of articles

- Immediate, unrestricted online access

- Rigorous Peer Review Process

- Authors Retain Copyrights

- Unique DOI for all articles 